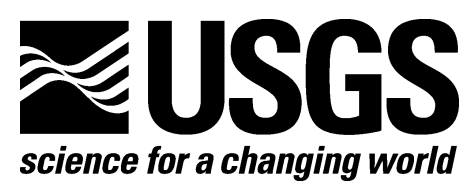

\title{
A Brief Test of the Hewlett-Packard MEMS Seismic Accelerometer
}

Brian D. Homeijer, ${ }^{1}$ Donald J. Milligan, ${ }^{1}$ and Charles R. Hutt ${ }^{2}$

Hewlett-Packard Co., Corvallis, Oregon, ${ }^{1}$ U.S. Geological Survey, Albuquerque, New Mexico²

Open-File Report 2014-1047

U.S. Department of the Interior

U.S. Geological Survey 


\section{U.S. Department of the Interior \\ SALLY JEWELL, Secretary}

\section{U.S. Geological Survey \\ Suzette M. Kimball, Acting Director}

U.S. Geological Survey, Reston, Virginia: 2014

For more information on the USGS - the Federal source for science about the Earth, its natural and living resources, natural hazards, and the environment-visit http://www.usgs.gov or call 1-888-ASK-USGS

For an overview of USGS information products, including maps, imagery, and publications, visit $h$ ttp://www.usgs.gov/pubprod

To order this and other USGS information products, visit $h$ ttp://store.usgs.gov

Suggested citation:

Homeijer, B.D., Milligan, D.J., and Hutt, C.R., 2014, A Brief Test of the Hewlett-Packard MEMS Seismic Accelerometer: U.S. Geological Survey Open-File Report 2014-1047, 18 p., http://dx.doi.org/10.3133/ofr20141047.

ISSN 2331-1258 (online)

Any use of trade, firm, or product names is for descriptive purposes only and does not imply endorsement by the U.S. Government.

Although this information product, for the most part, is in the public domain, it also may contain copyrighted materials as noted in the text. Permission to reproduce copyrighted items must be secured from the copyright owner. 


\section{Contents}

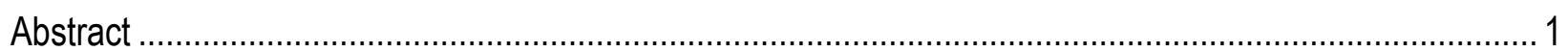

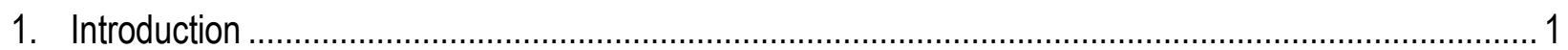

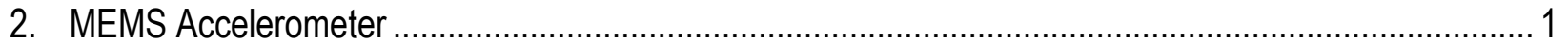

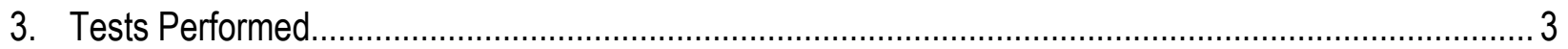

3.1 Accelerometer Calibration ................................................................................................

3.2 Data Logger Calibration....................................................................................................

3.3 Noise Level Test..........................................................................................................

3.4 Comparison of Higher Level Short-Period Signals ……………………………………......... 11

3.5 Comparison of Earthquake Signal ...................................................................................... 14

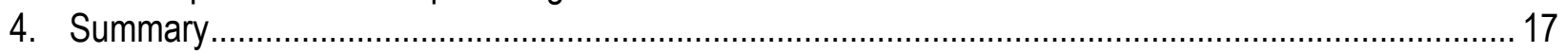

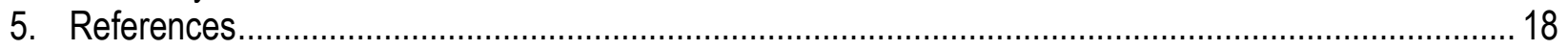

\section{Figures}

1. The latest generation of Hewlett-Packard MEMS seismic accelerometers ........................................ 2

2. Schematic cross section of the Hewlett-Packard MEMS seismic accelerometer die............................. 2

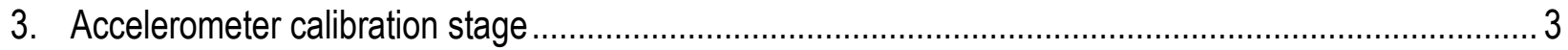

4. Accelerometer output during calibration sequence ……............................................................ 4

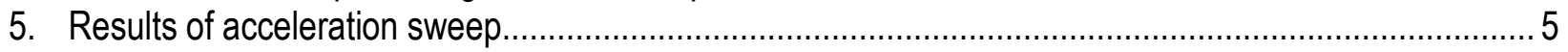

6. Digitizer (ADC) counts during application of the voltage reference .................................................. 6

7. Power spectral densities of shorted-inputs to digitizer adjusted for accelerometer and seismometer responses ......................................................................................................................

8. Experimental setup of the Hewlett-Packard MEMS accelerometer and Geotech GS-13 reference

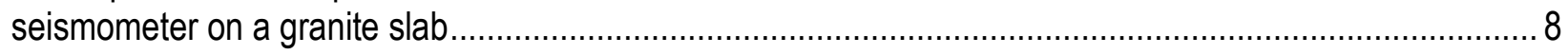

9. Time series data during low noise testing ............................................................................

10. Power spectral densities (PSDs) of Hewlett-Packard MEMS accelerometer and GS-13 seismometer

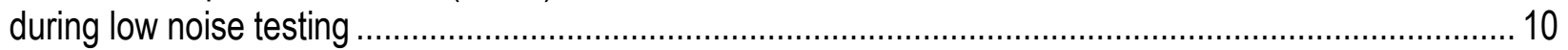

11. Coherence between the accelerometer and seismometer during low-noise testing ........................... 11

12. Time series data during short-period high-noise testing ............................................................ 12

13. Power spectral densities (PSDs) of Hewlett-Packard MEMS accelerometer and GS-13 seismometer

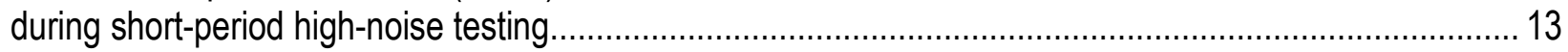

14. Coherence between the accelerometer and seismometer during short-period high-noise testing ...... 14

15. Time series data during Gulf of California magnitude 6.7 earthquake............................................ 15

16. Power spectral densities (PSDs) of HP MEMS accelerometer and GS-13 seismometer during Gulf of California magnitude 6.7 earthquake ................................................................................ 16

17. Coherence between the accelerometer and seismometer during Gulf of California magnitude 6.7

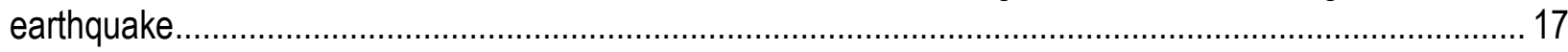

\section{Tables}

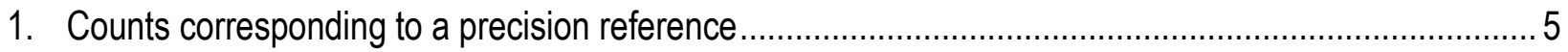

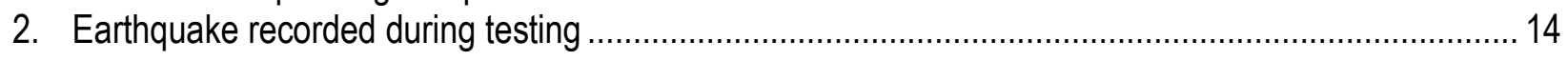




\section{Conversion Factors}

Inch/Pound to SI

\begin{tabular}{lll}
\hline \multicolumn{1}{c}{ Multiply } & By & To obtain \\
\hline foot (ft) & Length & \\
\hline SI to Inch/Pound & 0.3048 & meters $(\mathrm{m})$ \\
\hline \multicolumn{1}{c}{ Multiply } & & \\
\hline \multicolumn{2}{c}{ By } & \multicolumn{1}{c}{ To obtain } \\
\hline centimeter (cm) & Length & \\
meter (m) & 0.3937 & inch (in.) \\
\hline
\end{tabular}

The $E$ is defined as exponent and signifies 10 raised to the following power.

\section{Units of Measurement Defined}

Gravitational acceleration- $g$

Volt-V

Hertz-Hz

Decibel- $\mathrm{dB}$

Second-s

Volt per meter per second squared-V/m/s

Meter per second squared per square root of Hertz-m/s $\mathrm{s}^{2} / \sqrt{\mathrm{Hz}}$

Nano- $g$ per square root of Hertz- $\mathrm{n} g / \sqrt{ } \mathrm{Hz}$

Micro-g per square root of Hertz- $\mu g / \sqrt{ } \mathrm{Hz}$ 


\title{
A Brief Test of the Hewlett-Packard MEMS Seismic Accelerometer
}

\author{
By Brian D. Homeijer, ${ }^{1}$ Donald J. Milligan, ${ }^{1}$ and Charles R. Hutt²
}

Hewlett-Packard Co., Corvallis, Oregon, ${ }^{1}$ U.S. Geological Survey, Albuquerque, New Mexico²

\begin{abstract}
Testing was performed on a prototype of Hewlett-Packard (HP) Micro-ElectroMechanical Systems (MEMS) seismic accelerometer at the U.S. Geological Survey's Albuquerque Seismological Laboratory. This prototype was built using discrete electronic components. The self-noise level was measured during low seismic background conditions and found to be $9.8 \mathrm{ng} / \sqrt{\mathrm{Hz}}$ at periods below $0.2 \mathrm{~s}$ (frequencies above $5 \mathrm{~Hz}$ ). The six-second microseism noise was also discernible. The HP MEMS accelerometer was compared to a Geotech Model GS-13 reference seismometer during seismic noise and signal levels well above the self-noise of the accelerometer. Matching power spectral densities (corrected for accelerometer and seismometer responses to represent true ground motion) indicated that the HP MEMS accelerometer has a flat (constant) response to acceleration from $0.0125 \mathrm{~Hz}$ to at least $62.5 \mathrm{~Hz}$. Tilt calibrations of the HP MEMS accelerometer verified that the flat response to acceleration extends to $0 \mathrm{~Hz}$.

Future development of the HP MEMS accelerometer includes replacing the discreet electronic boards with a low-power application-specific integrated circuit (ASIC) and increasing the dynamic range of the sensor to detect strong motion signals above one gravitational acceleration, while maintaining the self-noise observed during these tests.
\end{abstract}

\section{Introduction}

This report describes the testing of a Micro-Electro-Mechanical Systems (MEMS) seismic accelerometer, developed by Hewlett-Packard Company (HP), at the U.S. Geological Survey's Albuquerque Seismological Laboratory. The testing was conducted the week of October 18, 2010. The primary goal of the testing was to measure the self-noise of the MEMS seismic accelerometer. The self-noise of a seismic sensor is the electronic and mechanical noise at the output of a seismometer or accelerometer in the presence of zero input ground motion (Hutt and others, 2010, p. 7). Alternatively, it can be the portion of a seismometer output signal not related to ground or case motion.

\section{MEMS Accelerometer}

The HP MEMS accelerometer is being developed for seismic imaging applications. It is a capacitive sensor using HP's surface electrode technology (Walmsley, and others, 2009), shown 
in figure 1. The MEMS accelerometer is fabricated from three separate, single crystal silicon wafers (the cap, rotor, and stator wafers) bonded together and singulated to produce a sensing mass that is packaged in vacuum at the wafer level, as shown in figure 2 (Homeijer, and others, 2011). The sensor is a single-axis accelerometer that can achieve full dynamic range regardless of the orientation of the sensitive axis (the axis along which acceleration is sensed) by using three-phase capacitive sensing (Walmsley, and others, 2010). The electronic functions needed to drive the accelerometer and detect the low noise signal are performed by custom, discreet electronics boards. In the future, these functions will be performed by a custom, low-power, analog, mixed-signal application-specific integrated circuit (ASIC), which is currently under development. For the current testing, the accelerometer and electronics are contained in an aluminum enclosure $(11 \times 7 \times 9 \mathrm{~cm})$.

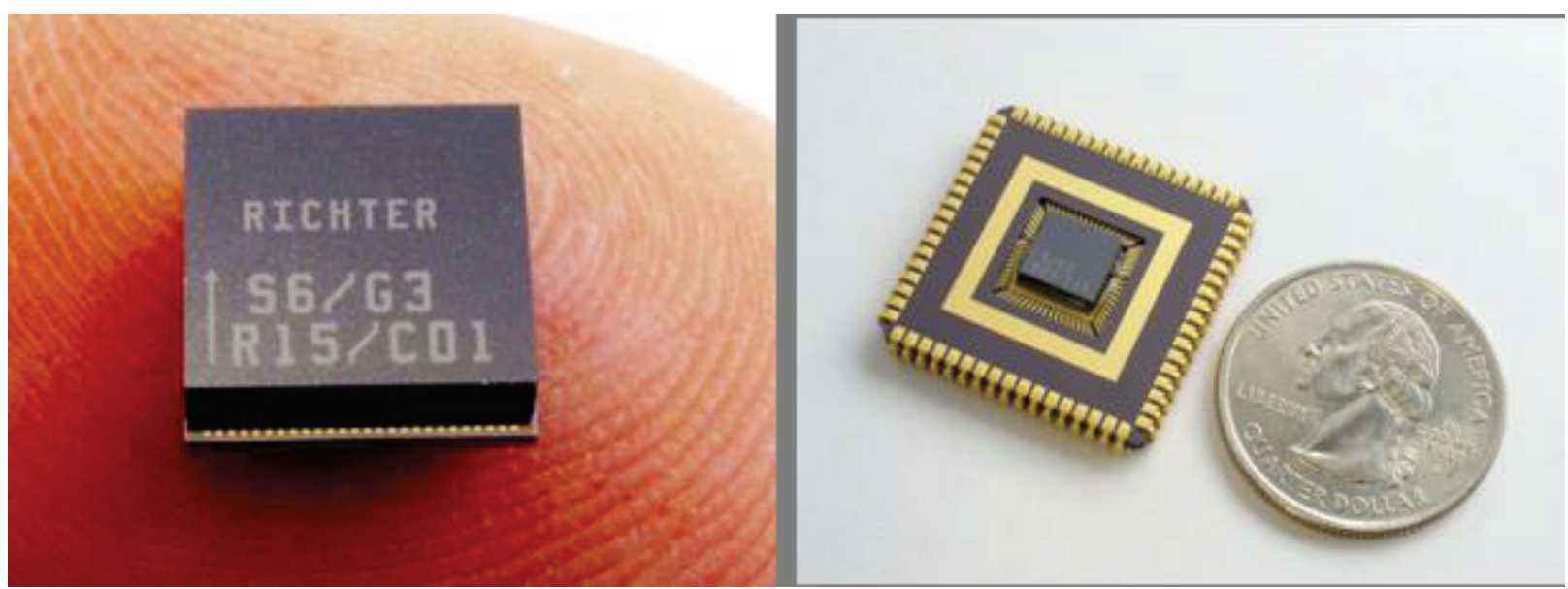

Figure 1. The latest generation of Hewlett-Packard MEMS seismic accelerometers. The accelerometer die is on the left. On the right is the die packaged in a prototype 68-pin plastic leaded chip carrier (PLCC) referenced to a quarter.

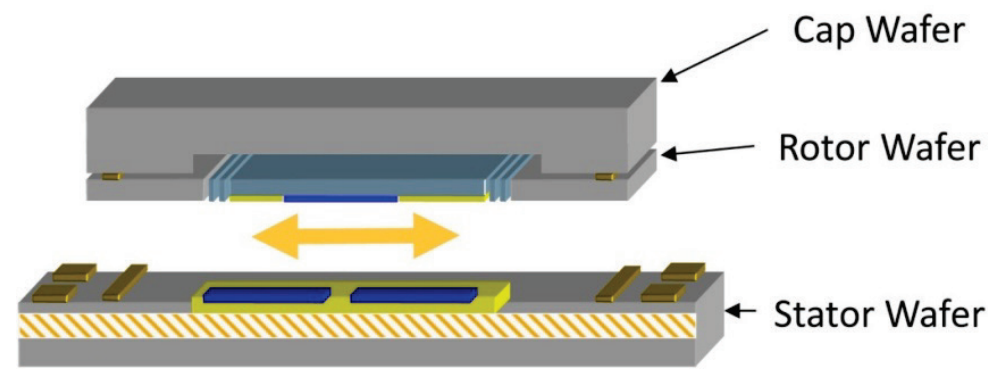

Figure 2. Schematic cross section of the Hewlett-Packard MEMS seismic accelerometer die (dimensions are $6.8 \mathrm{~mm} \times 6.8 \mathrm{~mm}$ ). 


\section{Tests Performed}

The following tests were performed:

3.1) Accelerometer calibration

3.2) Data logger (digitizer) calibration

3.3) Self-noise level test in underground tunnel.

3.4) Comparison to reference sensors of short-period (high frequency) signals.

3.5) Comparison to reference sensors of long-period signals from earthquake.

\subsection{Accelerometer Calibration}

The scale factor of the accelerometer was determined using an automated procedure to record the voltage output of the accelerometer for a range of accelerations applied by gravity at varying angles. These angles were applied using a stepper motor with a 50:1 reduction gear head. There are 409,600 encoder positions per revolution. The motorized rotation stage with the HP accelerometer is shown in figure 3.

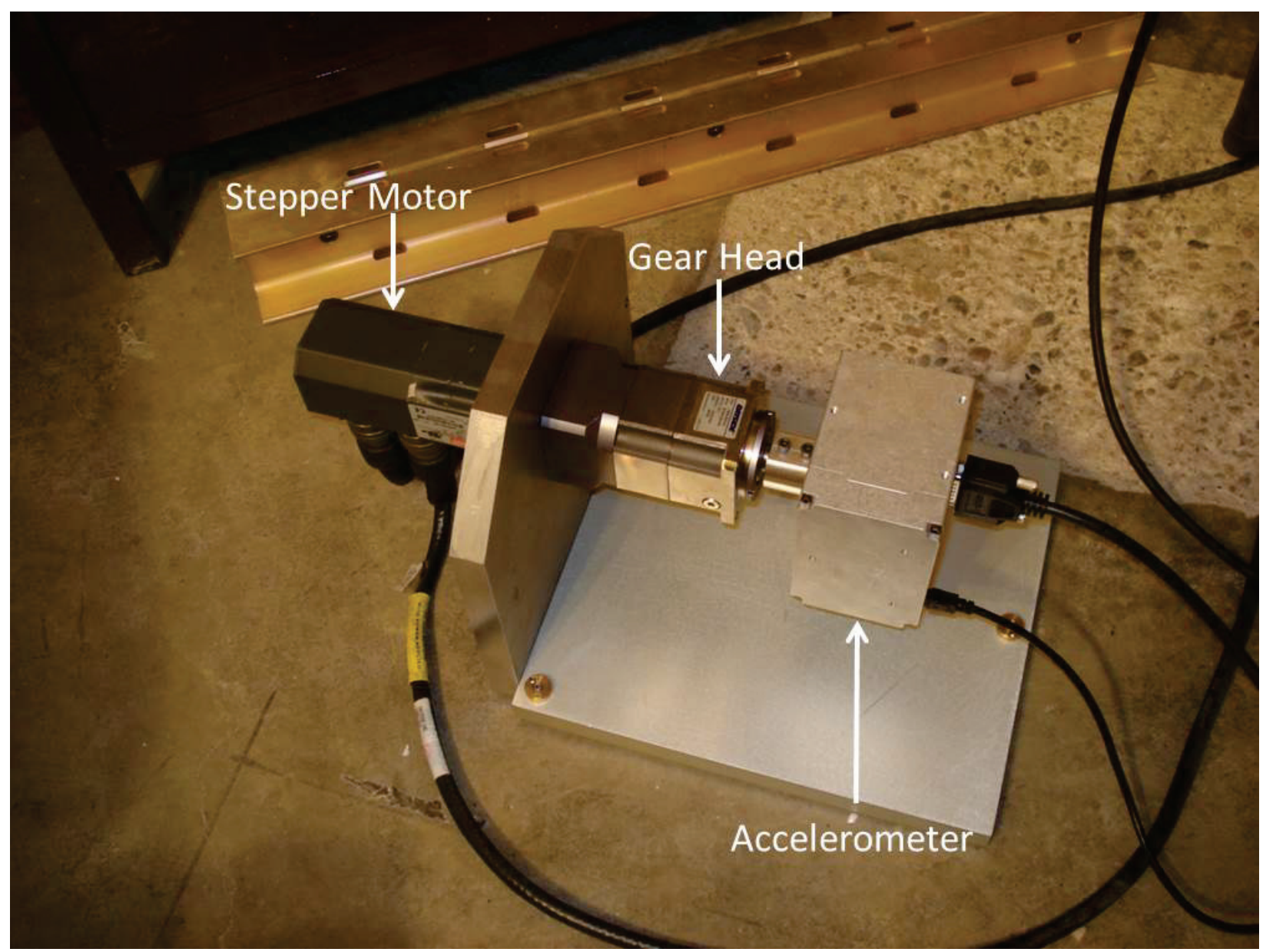

Figure 3. Accelerometer calibration stage. 
The procedure for calibration starts by nulling the accelerometer output at a zero- $g$ orientation. The accelerometer was rotated in specified increments to a maximum acceleration in the negative direction. Each position was approached counterclockwise to prevent backlash in the reduction gears. After each rotation, a delay of $5 \mathrm{~s}$ was allowed for the vibrations to settle and the output was averaged for $5 \mathrm{~s}$. The accelerometer was then rotated in increments to a maximum acceleration in the positive direction. Finally, the accelerometer was rotated in increments back to zero. The acceleration sequence is shown in figure 4 . With this method, two accelerometer outputs were measured for each acceleration — one during a decreasing acceleration sweep and the other for an increasing acceleration sweep.
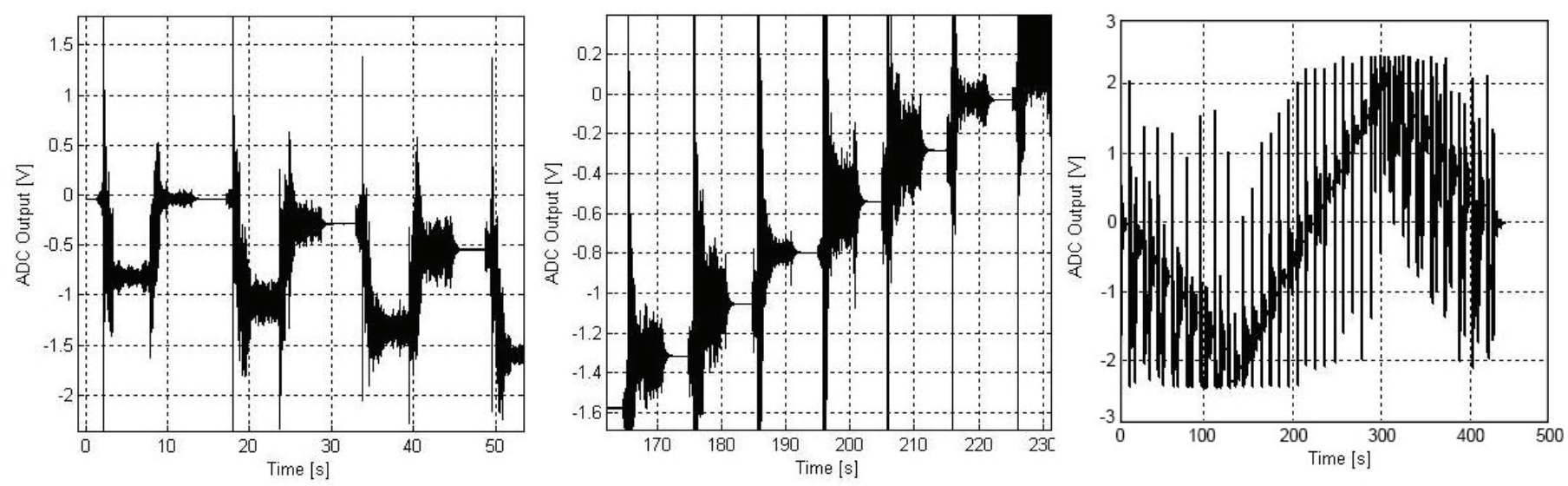

Figure 4. Accelerometer output during calibration sequence (decreasing levels of zoom from left to right). ADC, analog-to-digital converter.

The accelerometer output voltage versus acceleration is plotted in figure 5 . The calibration determined for the device for the current setup has a scale factor of $9.37 \mathrm{~V} / \mathrm{m} / \mathrm{s}^{2}$. A linear regression was calculated on the output of the accelerometer, resulting in determining a coefficient $\left(R^{2}\right)$ of 0.9937 . No hysteresis was observed. 


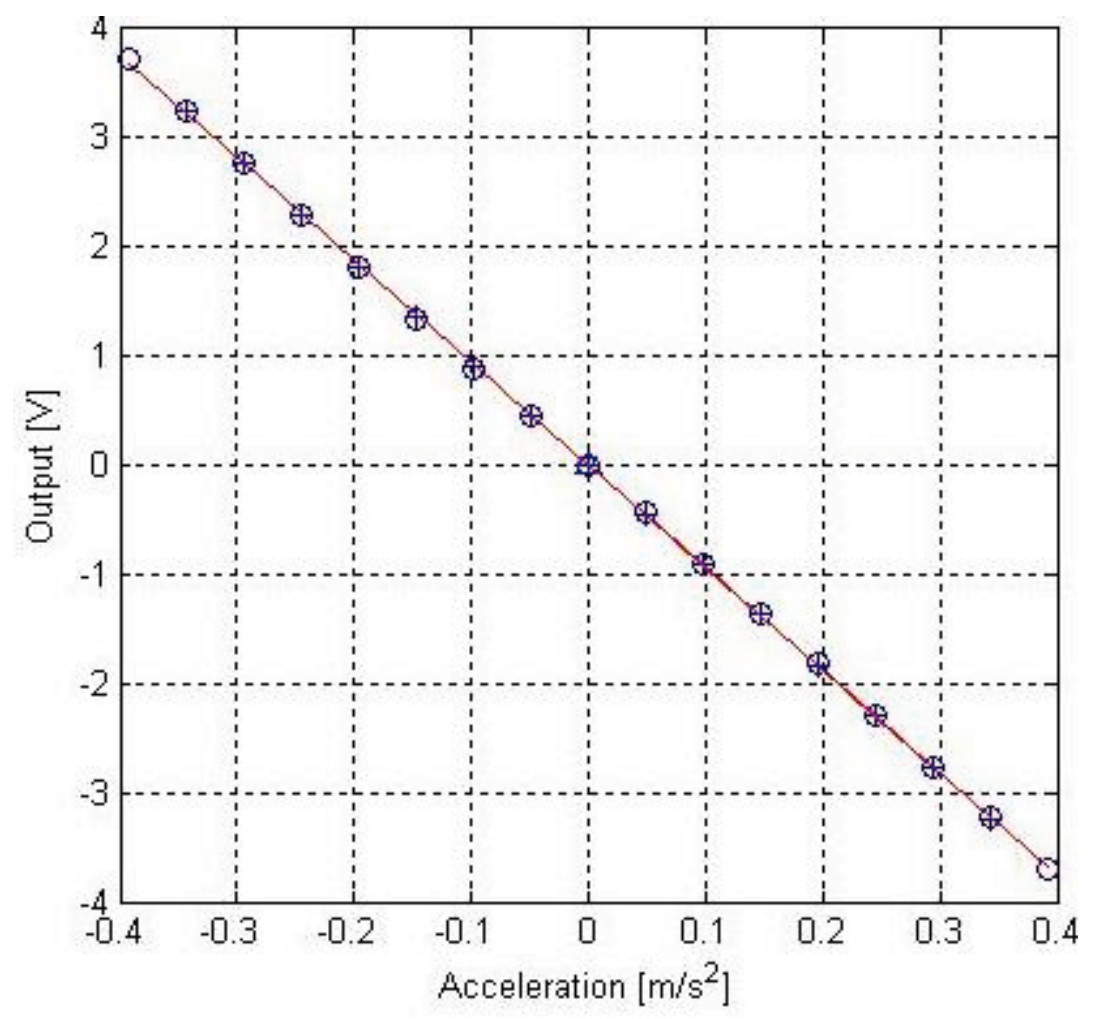

Figure 5. Results of acceleration sweep. The red line represents a linear regression fit to the data.

\subsection{Data Logger Calibration}

All data were recorded using a Kinemetrics Quanterra Q330HR data logger (also known as digitizer or analog-to-digital converter or ADC) with preamplifier gains set to 20. The accuracy of the readings was verified by calibrating the channels used to connect to the HP MEMS sensor and the Geotech Model GS-13 reference seismometer. A Calibrators Inc. Model DVC-350A precision reference was connected to the inputs of the digitizer. Input voltages of $0 \mathrm{~V},+0.5000 \mathrm{~V}$, and $-0.5000 \mathrm{~V}$ were applied to the respective channels. Figure 6 shows the results from the test and table 1 shows the corresponding counts per channel. The resulting sensitivities are $8.4165 \mathrm{E}+6$ counts/V and $3.3616 \mathrm{E}+7$ counts/V for the GS-13 and HP MEMS, respectively ( $\mathrm{E}$ is defined as the exponent and signifies 10 raised to the following power).

Table 1. Counts corresponding to a precision reference.

\begin{tabular}{lcrc}
\hline Voltage Applied $(\mathbf{V})$ & $\mathbf{0 ~ V}$ & $\mathbf{+ 0 . 5 0 0 0 ~ V}$ & \multicolumn{1}{c}{$\mathbf{0 . 5 0 0 0 ~ V}$} \\
\hline GS-13 counts & $1.1360 \mathrm{E}+03$ & $4.2084 \mathrm{E}+06$ & $-4.2081 \mathrm{E}+06$ \\
HP MEMS counts & $3.5300 \mathrm{E}+03$ & $1.6808 \mathrm{E}+07$ & $-1.6808 \mathrm{E}+07$ \\
\hline
\end{tabular}




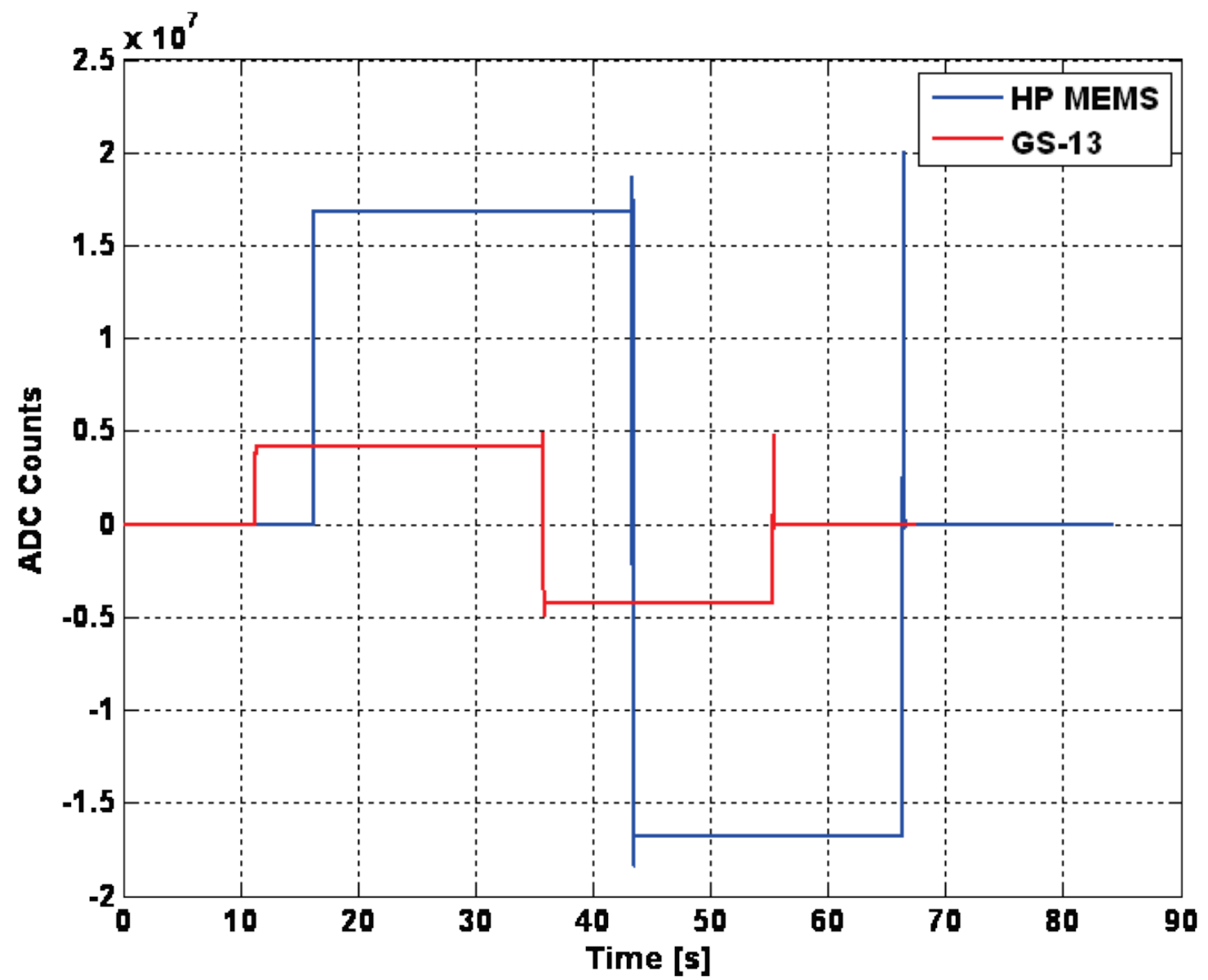

Figure 6. Digitizer (ADC) counts during application of the voltage reference.

The inputs to the digitizer were then shorted to give a minimum detectable acceleration for each sensor (accelerometer or seismometer) channel. The respective outputs are adjusted for the response of each sensor and shown in figure 7. 


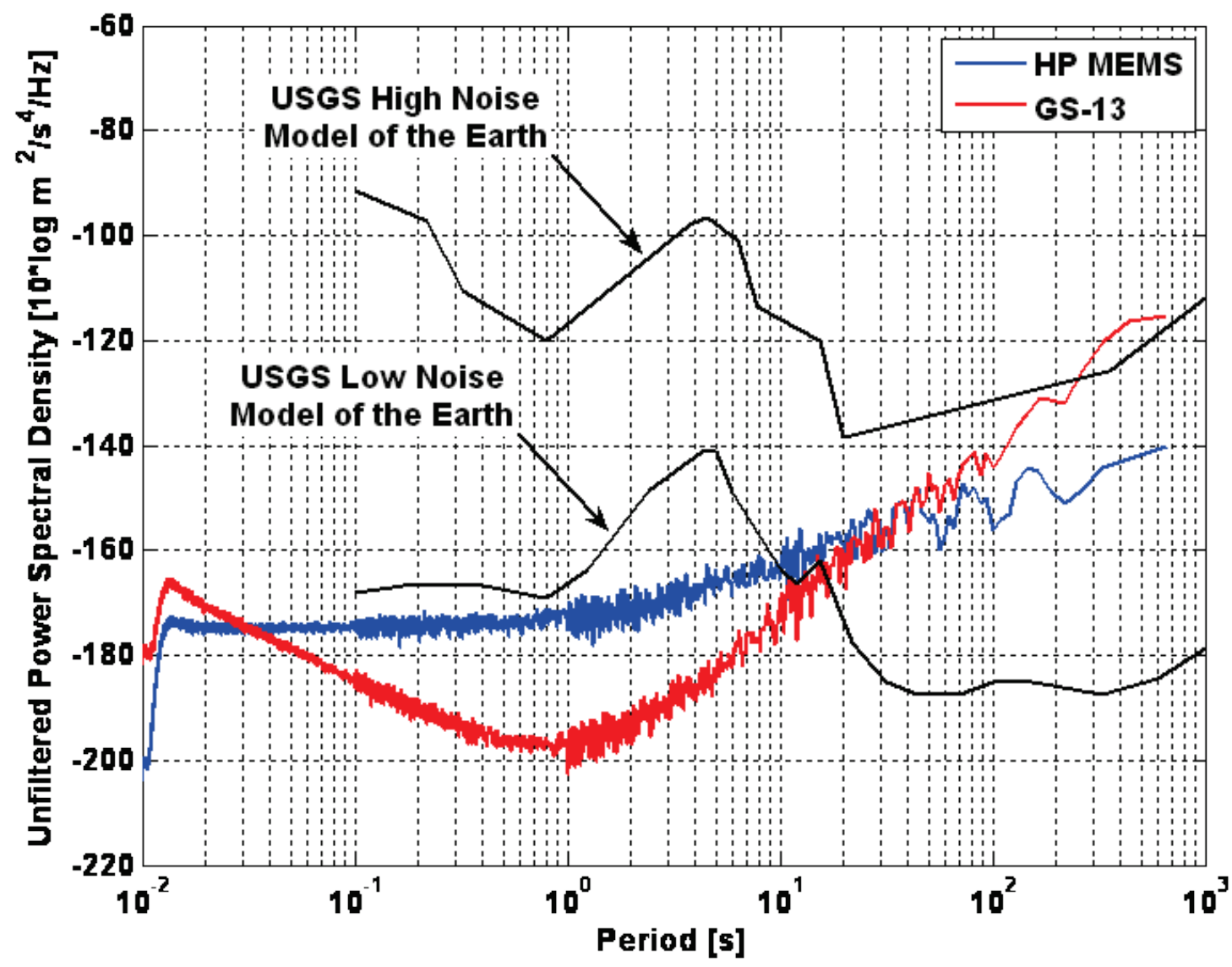

Figure 7. Power Spectral Density (PSD) plots of digitizer shorted-input 200 sample-per-second data, corrected for sensor response to produce equivalent ground acceleration. The variance changes at 0.1 $\mathrm{s}$ and $1 \mathrm{~s}$ period due to the smoothing algorithm. Data shown with the USGS low- and high-noise models of the Earth (Peterson, 1993).

\subsection{Noise Level Test}

To determine the self-noise of the HP MEMS accelerometer, the accelerometer along with the GS-13 seismometer were placed in close proximity to each other on a block of granite. The granite slab and both sensors were supported by three stainless steel feet (three-point support) to avoid any rocking noise. The experimental setup can be seen in figure 8 . The underground seismic vault (where the tests were conducted) was vacated and the devices were allowed to run for an extended period of time, waiting for a low noise period. Once the background noise, measured by the GS-13, was confirmed to be below the estimated self-noise of the HP MEMS accelerometer, data were collected for analysis. 


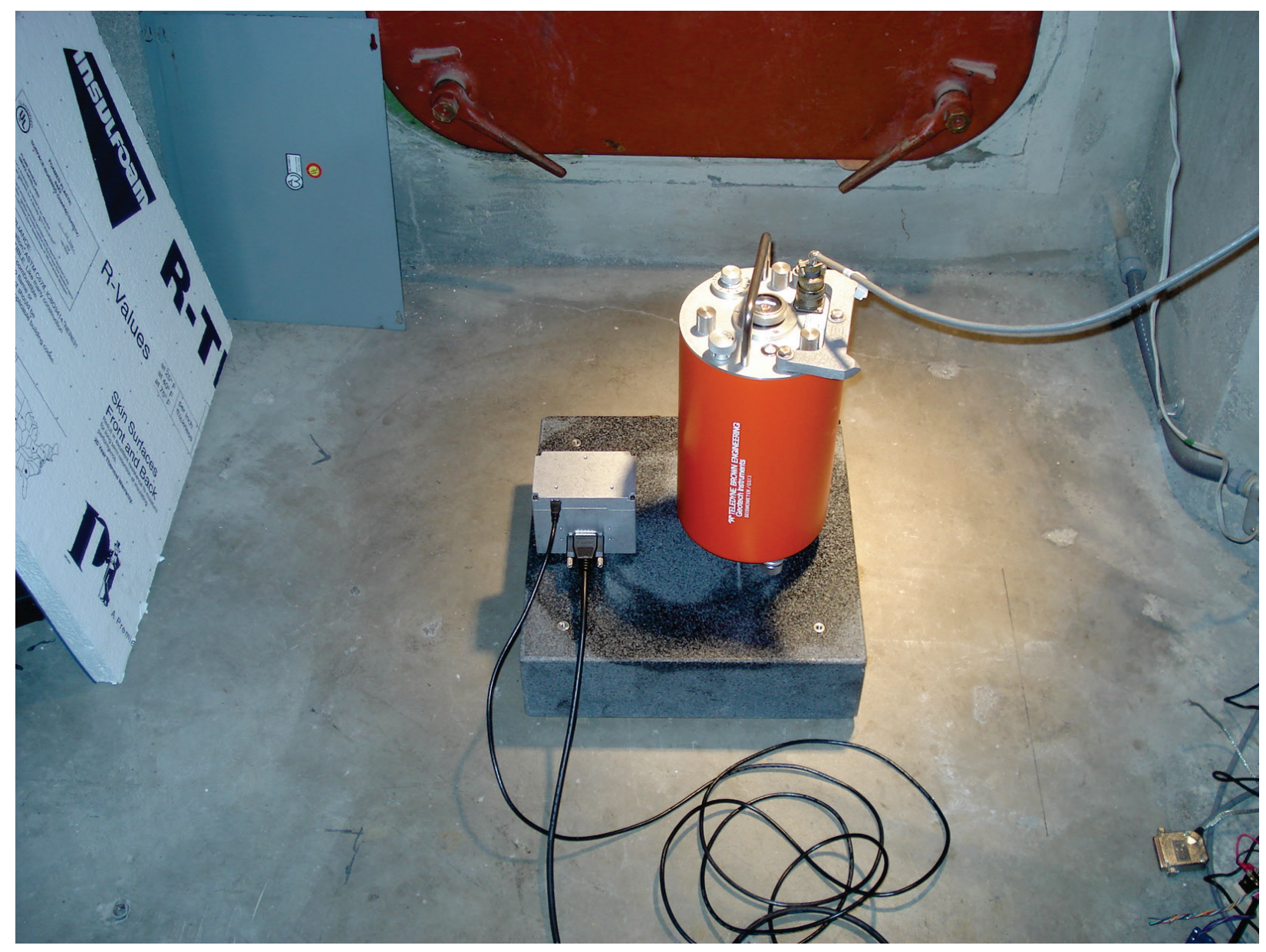

Figure 8. Experimental setup of the Hewlett-Packard MEMS seismic accelerometer and Geotech GS-13 reference seismometer on a granite slab.

A low-noise segment of $4000 \mathrm{~s}$ was selected, and the time series data for this analysis are plotted in figure 9. The power spectral density (PSD) and coherence are plotted in figure 10 and figure 11, respectively. The data show that the HP MEMS accelerometer has a self-noise level just below 1E-7 meter per second squared per square-root hertz $\left(\mathrm{m} / \mathrm{s}^{2} / \sqrt{\mathrm{Hz}} ;-140\right.$ decibel $[\mathrm{dB}]$ on the PSD plot, equal to 10 nano-g per square-root hertz $(\mathrm{ng} / \sqrt{\mathrm{Hz}}))$ at periods less than $0.125 \mathrm{~s}$ (frequencies greater than $8 \mathrm{~Hz}$ ). The noise floor is constant (flat) from about $62 \mathrm{~Hz}$ to $8 \mathrm{~Hz}$ (periods from $0.016 \mathrm{~s}$ to $0.125 \mathrm{~s})$ and reaches $1.57 \mathrm{E}-7 \mathrm{~m} / \mathrm{s}^{2} / \sqrt{\mathrm{Hz}}(16 \mathrm{ng} / \sqrt{\mathrm{Hz}})$ at $1 \mathrm{~Hz}(1 \mathrm{~s}$ period). The noise level continues to rise at lower frequencies (longer periods) and crosses $1 \mathrm{E}-5$ $\mathrm{m} / \mathrm{s}^{2} / \sqrt{\mathrm{Hz}}(1 \mu \mathrm{g} / \sqrt{\mathrm{Hz}})$ at $200 \mathrm{~s}$ period $(0.005 \mathrm{~Hz})$. The HP MEMS accelerometer was also able to resolve (at a signal-to-noise ratio of approximately one) the micro-seismic peak (at approximately $7 \mathrm{~s}$ period) caused by ocean waves. This was confirmed by observing a maximum in the coherence around a period of $7 \mathrm{~s}$. 

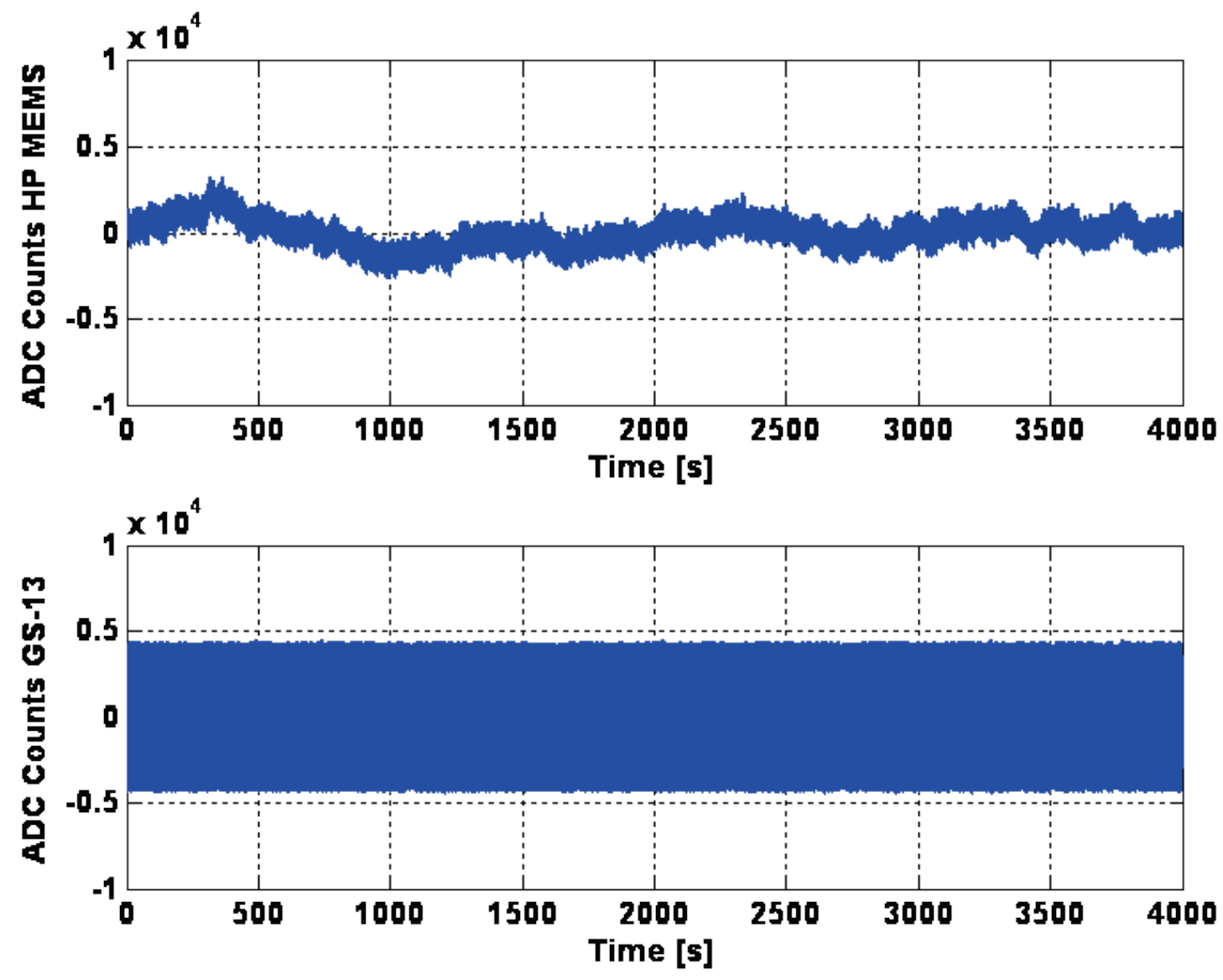

Figure 9. Time series data during low noise testing. The GS-13 time series is dominated by $60 \mathrm{~Hz}$ noise, which is most likely from electromagnetic induction from the main power lines. ADC, analog-to-digital converter. 


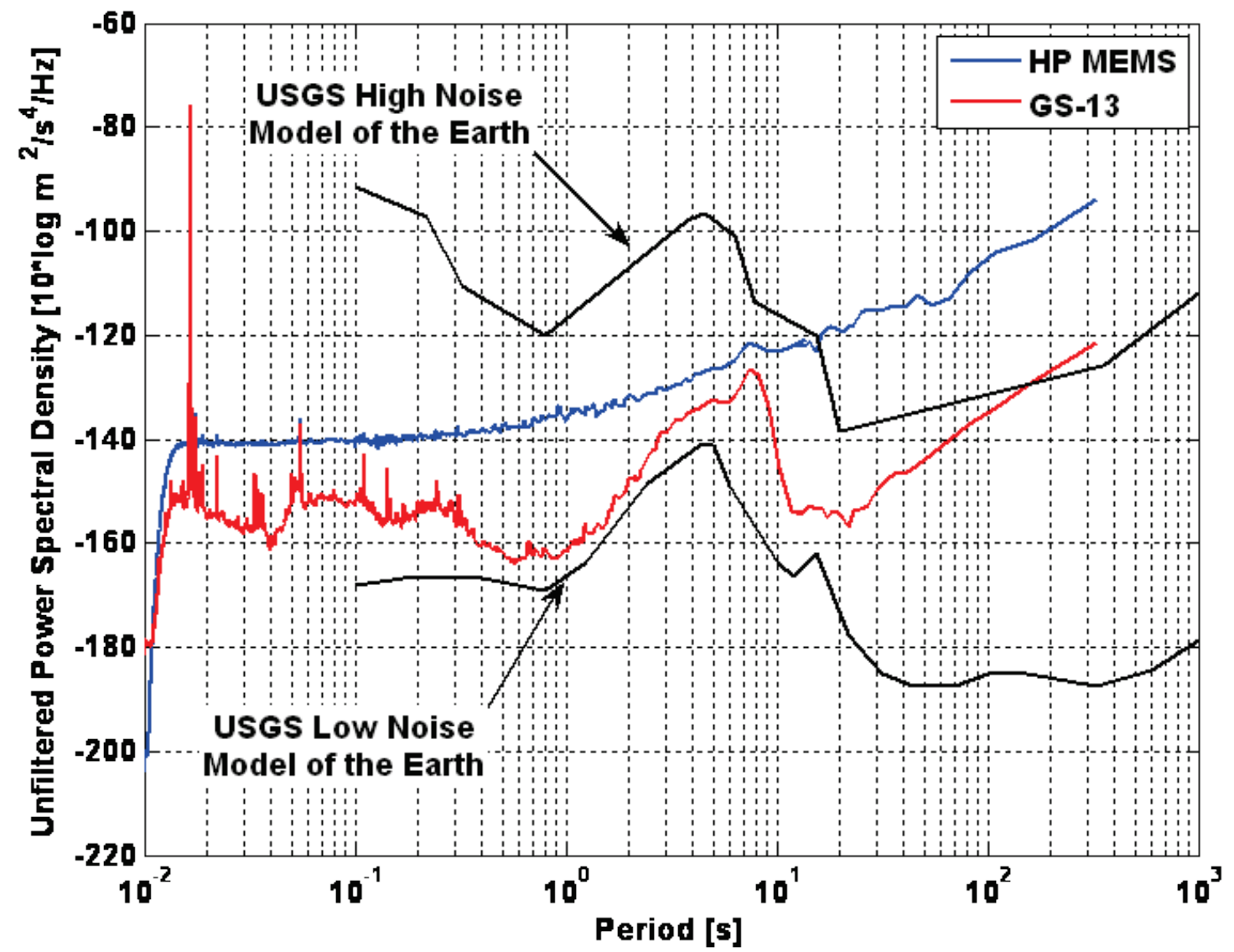

Figure 10. Power spectral densities (PSDs) of Hewlett-Packard MEMS seismic accelerometer and GS-13 reference seismometer during low noise testing. Note that the micro-seismic peak at around $7 \mathrm{~s}$ period seen by the GS-13 PSD is also visible in the HP MEMS PSD. The spike at 0.0167 s period in the GS$13 \mathrm{PSD}$ is caused by $60 \mathrm{~Hz}$ pickup in the seismometer coil. Also plotted are the USGS high and low noise models of the Earth (Peterson, 1993). 


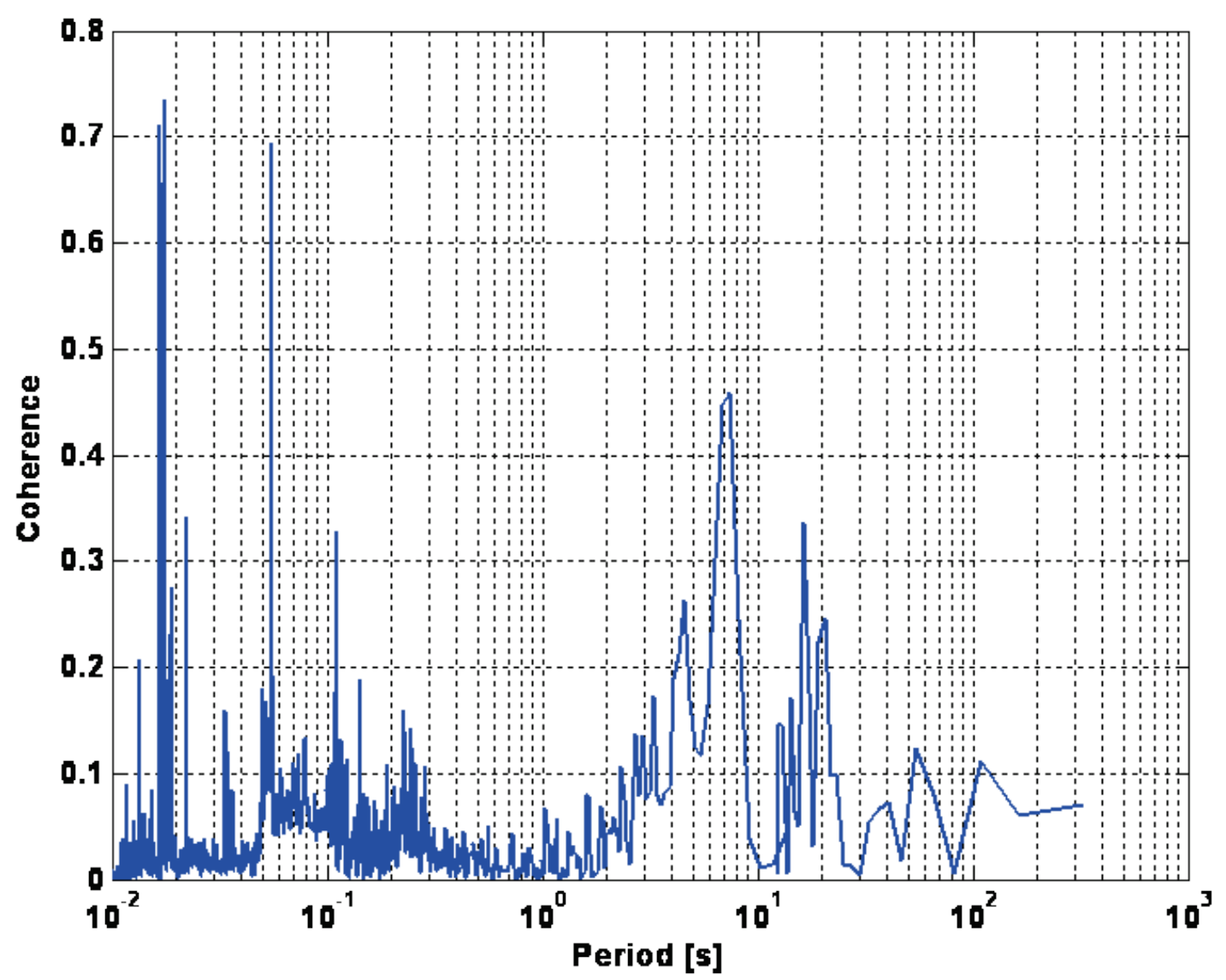

Figure 11. Coherence between the accelerometer and seismometer during low-noise testing. The coherence peak at $7 \mathrm{~s}$ period is evidence that the Hewlett-Packard MEMS seismic accelerometer is observing the micro-seismic peak from ocean waves.

\subsection{Comparison of Higher Level Short-Period Signals}

A comparison of the HP MEMS seismic accelerometer with the GS-13 seismometer was made for higher amplitudes of short-period noise. For this test, the GS-13 seismometer and the HP MEMS accelerometer were placed in the same configuration as the low-noise test. Data were logged from both sensors while a car was leaving the underground test vault area on a gravel road. The data recorded for this analysis are shown in figure 12. The PSD during the test is shown in figure 13. The two sensors (accelerometer and seismometer) show excellent agreement from $0.01 \mathrm{~s}$ period to $0.1 \mathrm{~s}$ period $(10 \mathrm{~Hz}$ to $100 \mathrm{~Hz})$. At longer periods, the seismic background energy level drops below the noise level of the HP accelerometer. This is confirmed with a drop in coherence as seen in figure 14 . 

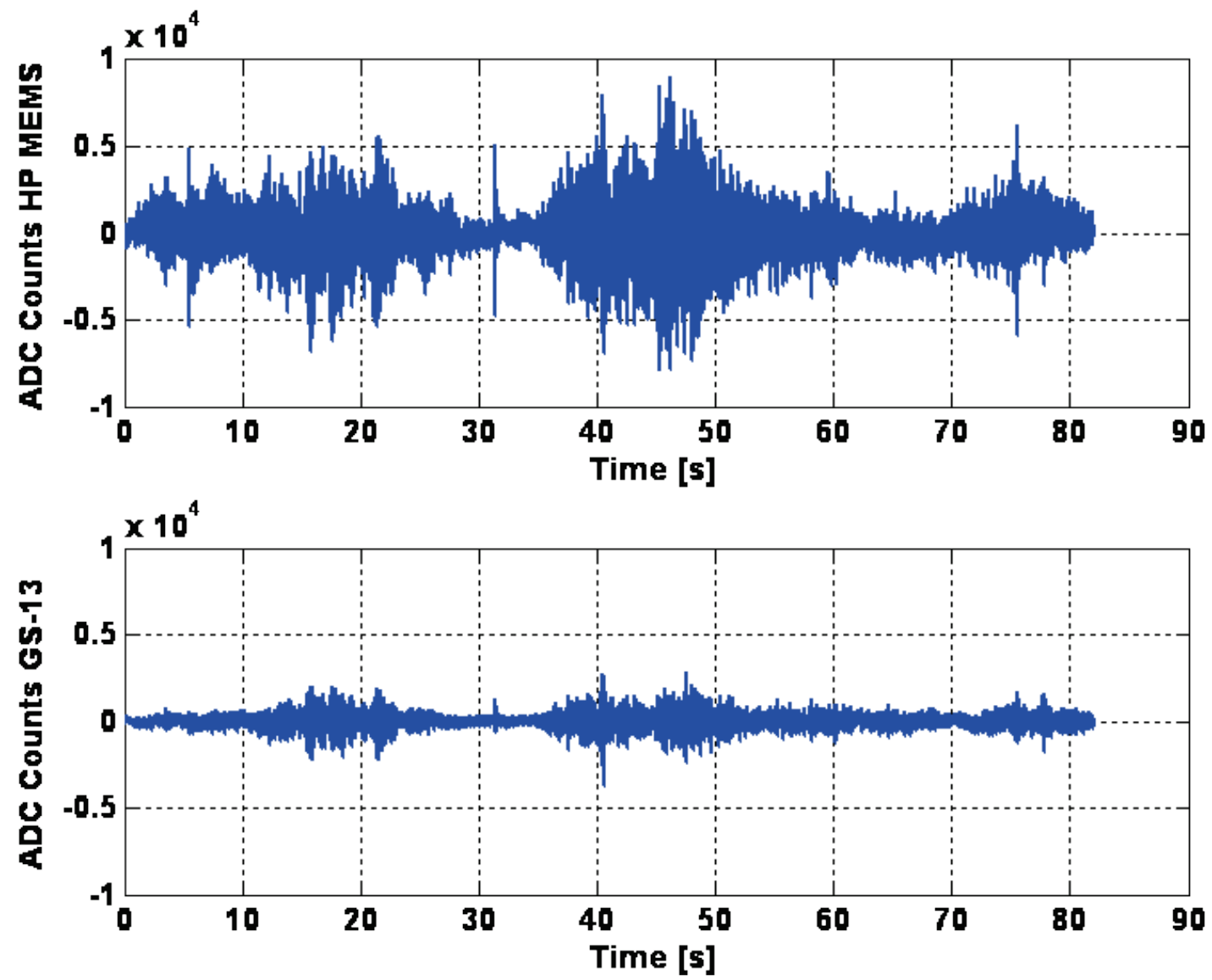

Figure 12. Time series data during short-period high-noise testing. ADC, analog-to-digital converter. 


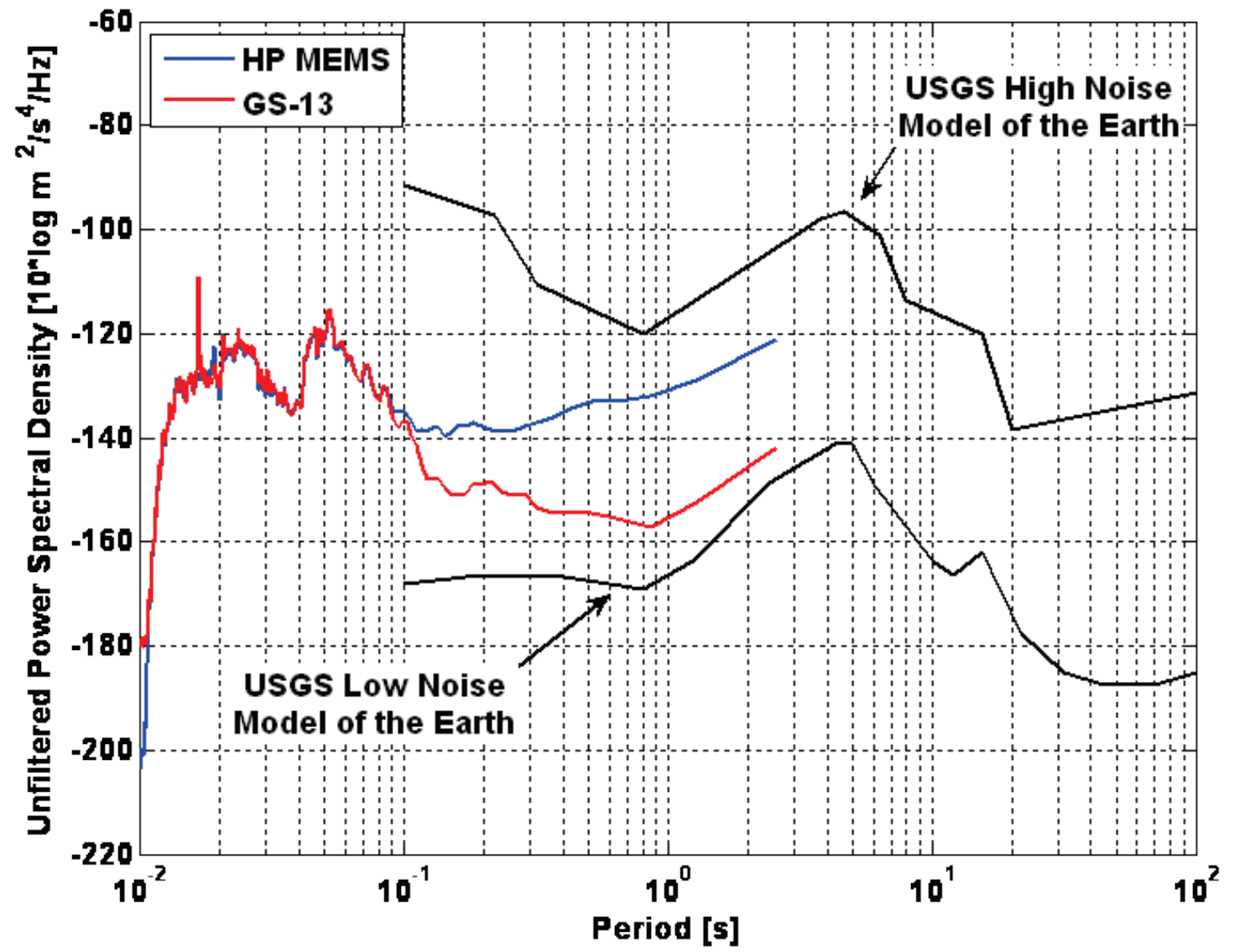

Figure 13. Power spectral densities (PSDs) of Hewlett-Packard MEMS seismic accelerometer and GS-13 seismometer during short-period high-noise testing. The spike in the GS-13 PSD at $0.0167 \mathrm{~s}$ period is caused by $60 \mathrm{~Hz}$ pickup in the seismometer coil. Also plotted are the USGS high- and low-noise models (Peterson, 1993). 


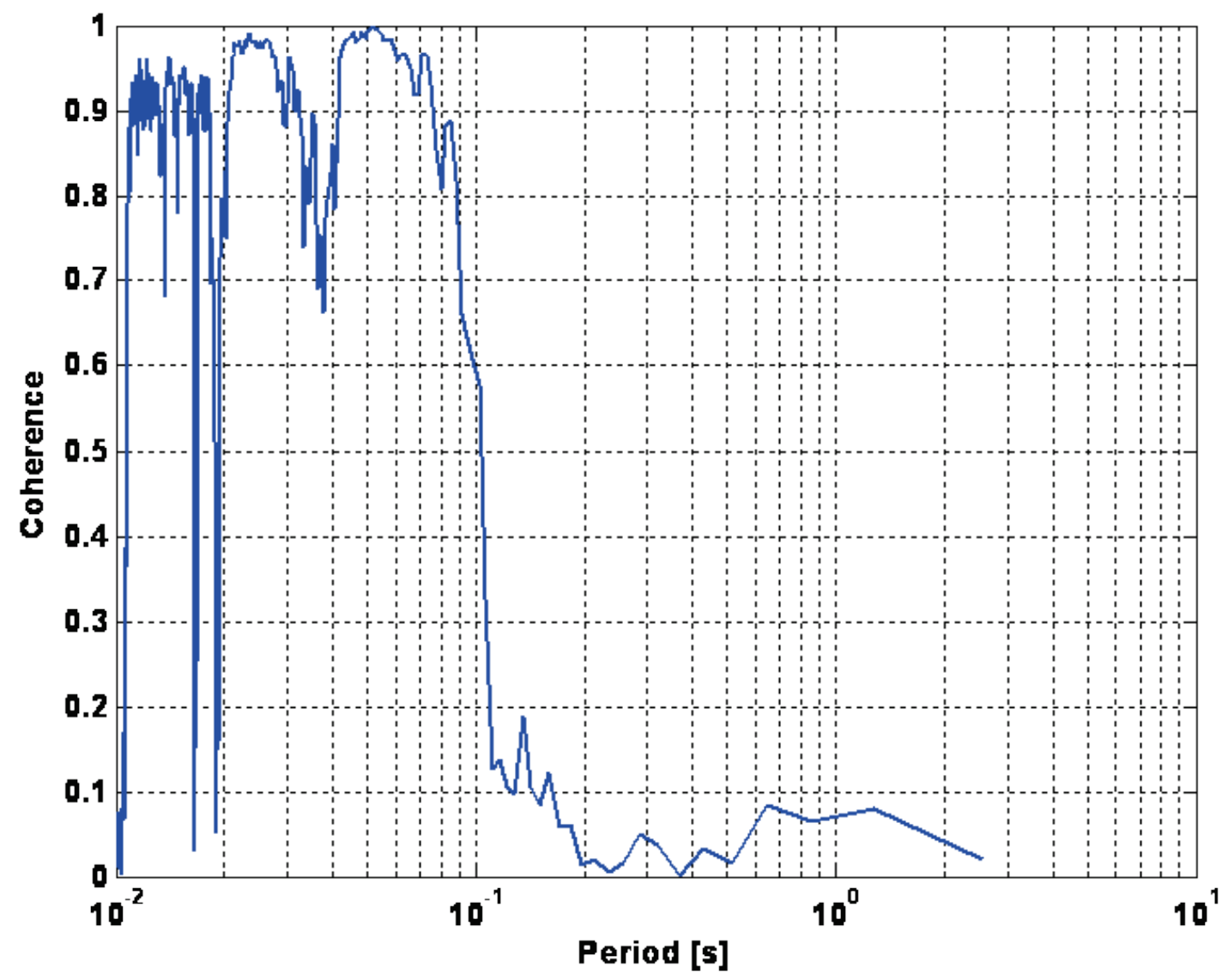

Figure 14. Coherence between the accelerometer and seismometer during short-period high-noise testing.

\subsection{Comparison of Earthquake Signal}

Data from the GS-13 seismometer and the HP MEMS accelerometer were also recorded during an earthquake in the Gulf of California. The earthquake parameters are summarized in table 2 .

Table 2. Earthquake recorded during testing.

\begin{tabular}{ccccccc}
\hline Magnitude & UTC Date and Time & $\begin{array}{c}\text { Latitude } \\
\text { (degrees) }\end{array}$ & $\begin{array}{c}\text { Longitude } \\
\text { (degrees) }\end{array}$ & Depth & Region & $\begin{array}{c}\text { Epicentral } \\
\text { Distance }\end{array}$ \\
\hline 6.7 & $\begin{array}{c}10 / 21 / 2010 \\
17: 53: 14 \text { (Day 294) }\end{array}$ & 24.84 & 109.17 & $10 \mathrm{~km}$ & $\begin{array}{c}\text { Gulf of } \\
\text { California }\end{array}$ & $10.35^{\circ}$ \\
\hline
\end{tabular}

Source: earthquake.usgs.gov 
Figure 15 shows the time series of the vertical waveforms from the two sensors (seismometer and accelerometer) during the earthquake. Figure 16 shows the PSDs of the two sensors (seismometer and accelerometer). These waveforms show excellent agreement between $0.5 \mathrm{~s}$ and $40 \mathrm{~s}$ periods $(0.025 \mathrm{~Hz}$ to $2 \mathrm{~Hz})$, indicating that this earthquake signal is well above the self-noise levels of both the GS-13 seismometer and the HP MEMS accelerometer in this frequency band and that the transfer function used for the HP MEMS accelerometer (flat response to acceleration) is correct. In addition, there is excellent coherence above one second period, shown in figure 17.
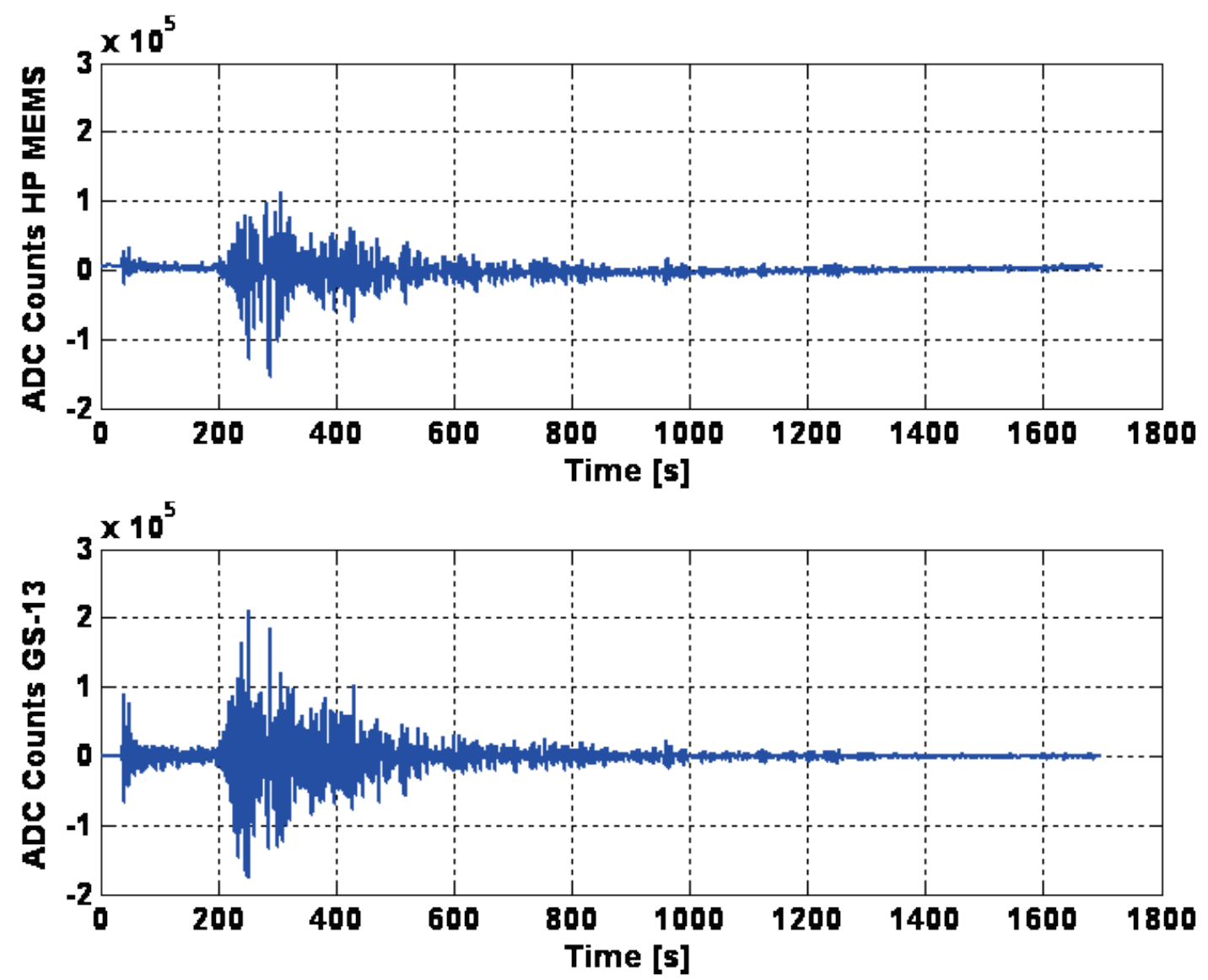

Figure 15. Time series data during Gulf of California magnitude 6.7 earthquake. ADC, analog-to-digital converter. 


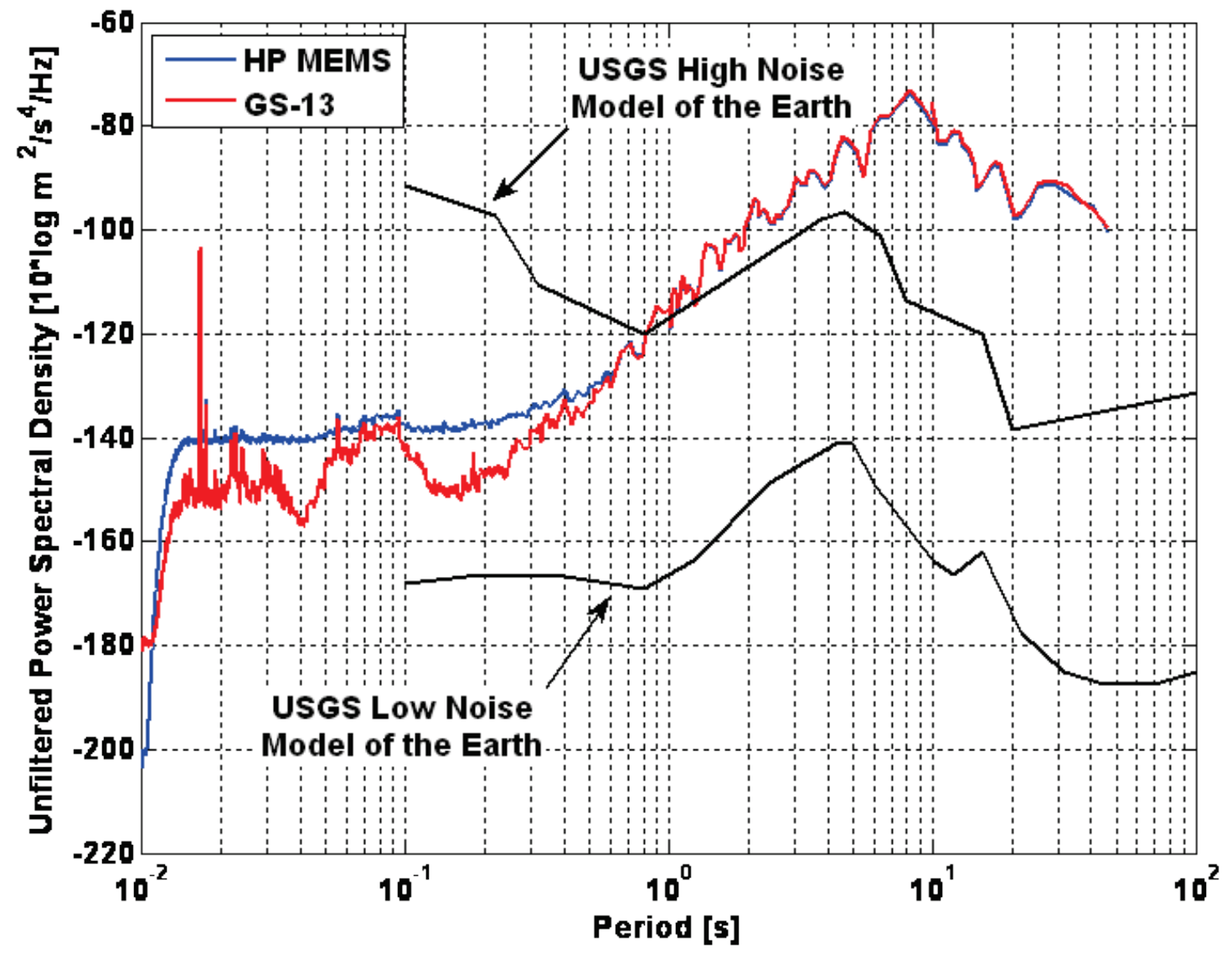

Figure 16. Power spectral densities (PSDs) of HP MEMS accelerometer and GS-13 seismometer during Gulf of California magnitude 6.7 earthquake. Also plotted are the USGS high- and low-noise models of the Earth (Peterson, 1993). 


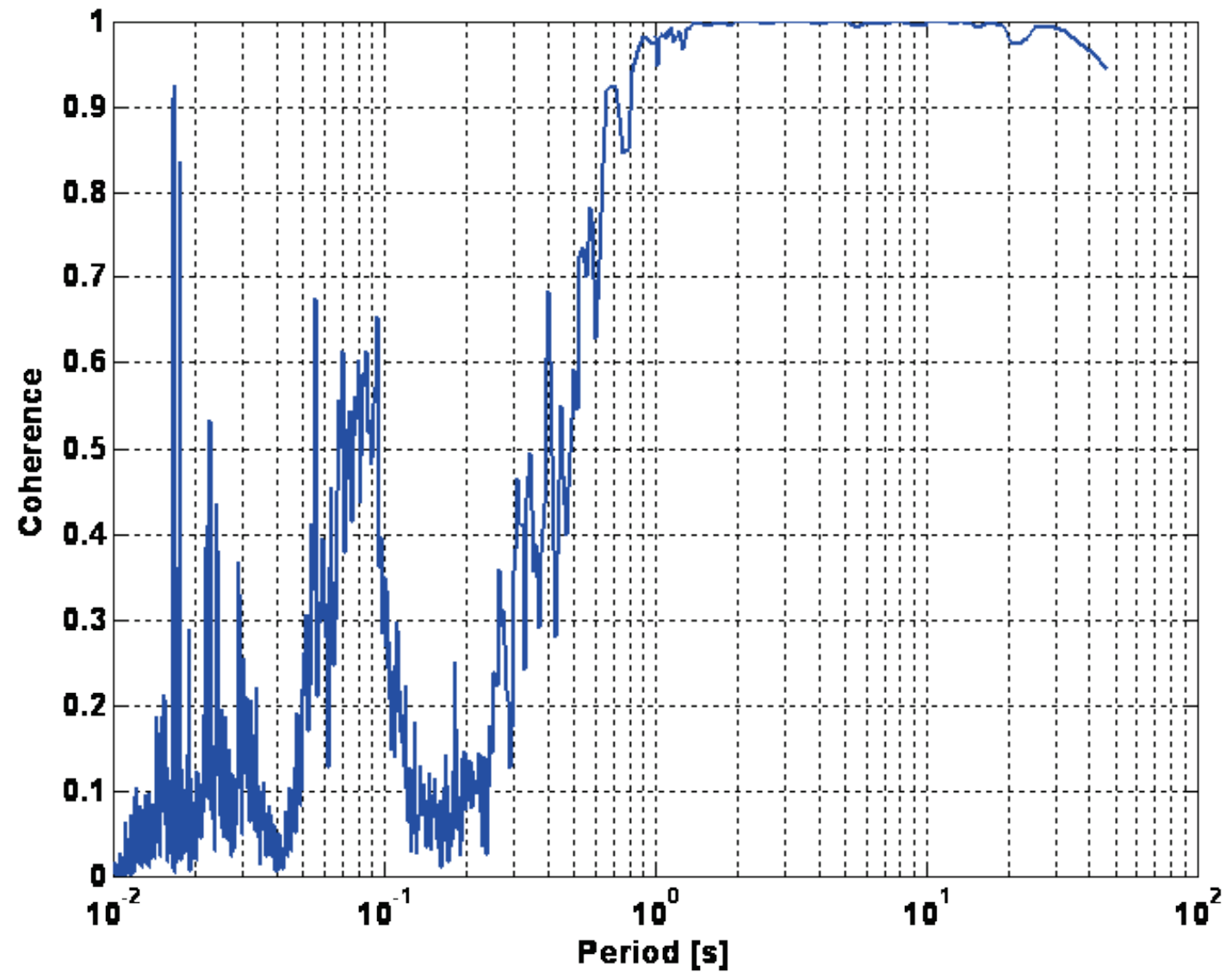

Figure 17. Coherence between the accelerometer and the seismometer during Gulf of California magnitude 6.7 earthquake.

\section{Summary}

Testing was performed on the Hewlett-Packard Micro-Electro-Mechanical Systems (MEMS) seismic accelerometer at the U.S. Geological Survey's Albuquerque Seismological Laboratory. The sensor was calibrated and the scale factor determined using a linear fit of the response to acceleration on a tilt table. The self-noise level was measured and found to be $9.8 \mathrm{ng} / \sqrt{\mathrm{Hz}}$ at periods below $0.2 \mathrm{~s}$ (frequencies above $5 \mathrm{~Hz}$ ). The seven-second microseism noise was also discernible. The HP MEMS accelerometer was compared to a Geotech Model GS-13 reference seismometer under high background noise conditions at high frequencies and their respective power spectral densities (PSDs) are nearly identical down to the shortest periods. Data were also collected during a magnitude 6.7 earthquake in the Gulf of California. Power spectral densities (PSDs) from data collected by the HP MEMS accelerometer and the GS-13 seismometer during the earthquake are nearly identical at periods up to $80 \mathrm{~s}$, indicating a flat response to acceleration at low frequencies and a good signal-to-noise ratio for the earthquake signal. 
Future development of the HP MEMS accelerometer includes replacing the discrete electronic boards with a low power application-specific integrated circuit (ASIC) and increasing the dynamic range of the sensor to detect strong motion signals above one gravitational acceleration, while maintaining the self-noise observed during these tests.

\section{References}

Homeijer, Brian, Lazaroff, D., Milligan, Don, Alley, R.L., Wu, J., Szepesi, M., Bicknell, B., Zhang, Z., Walmsley, R.G., and Hartwell, R.G., 2011, Hewlett Packard's Seismic Grade MEMS Accelerometer, in Institute of Electrical and Electronics Engineers (IEEE) MEMS Conference, 24th, Cancun, Mexico, p. 585-588.

Hutt, C.R., Evans, J.R., Followill, Fred, Nigbor, R.L., and Wielandt, Erhard, 2010, Guidelines for standardized testing of broadband seismometers and accelerometers: U.S. Geological Survey Open-File Report, 2009-1295, 62 p.

Peterson, J.R., 1993, Observations and modeling of seismic background noise: USGS Open-File Report 93-322, at http://earthquake.usgs.gov/regional/asl/pubs/files/ofr93-322.pdf.

Walmsley, R.G., Hopcroft, M.A., Hartwell, P.G., Corrigan,G., Milligan, D., 2010, Three-Phase Capacitive Position Sensing, in IEEE Sensors Conference, 9th, Waikoloa, HI, p. 2658-2661.

Walmsley, R.G., Kiyama, L.K., Milligan, D.M., Alley, R.L., Erickson, D.L., and Hartwell, P.G., 2009, Micro-G silicon accelerometer using surface electrodes, in IEEE Sensors Conference, 8th: IEEE, Christchurch, New Zealand, p. 971-974.

ISSN 2331-1258 (online) http://dx.doi.org/10.3133/ofr20141047 